\title{
El arte, la muerte, la historia. El problema del tiempo y la historia en las reflexiones estéticas hegelianas
}

\section{Art, Death, History. The Problem of Time and History in Hegelian reflections on Aesthetics}

\author{
María Antonia GonZÁLEZ VALERIO \\ Facultad de Filosofía y Letras \\ Universidad Nacional Autónoma de México \\ mariantonia@magonzalezvalerio.com
}

Recibido: 01/02/2011

Aceptado: 20/06/2011

\section{Resumen}

Este texto lleva a cabo un análisis del papel que cumplen el tiempo y la historia dentro de la filosofía hegeliana, específicamente en la estética. Se parte de la idea de que en el siglo XIX se instaura radicalmente la relación entre arte y tiempo y se toma la estética hegeliana como paradigma de dicha relación. Desde el horizonte de la ontología estética, se reflexiona acerca del papel que cumplen el tiempo y la historia en el arte y se pregunta qué significa la construcción de una historia del arte y si el arte es esencialmente histórico. Asimismo, se investiga sobre las consecuencias de la introducción de tiempo e historia para la estética en su relación con la ontología, después se pregunta qué significa pensar el ser desde el tiempo y la historia. Se asume además que la historia es uno de los modos de ser del tiempo, mas no el único, y que por tanto, al arte corresponden también otro tipo de temporalidades. Desde los postulados históricos y temporales, se problematizan ideas como la universalidad de la belleza y la eternidad de la Idea.

Palabras clave: Estética hegeliana, ontología estética, historicidad, temporalidad, arte. 


\begin{abstract}
This paper analyzes the role that time and history have within Hegelian philosophy, particularly within Hegelian Aesthetics. One central idea is that during the XIX century the relationship between art and time is postulated very emphatically; the Hegelian Aesthetics are assumed in this paper as a paradigm of the afore mentioned relationship. From the point of view of the aesthetic ontology, the paper inquires about the roles that time and history have in the art field and also it questions what is the significance of the art history and if art is essentially historic. It investigates the theoretical consequences for the Ontology of the introduction of art and history in Aesthetics. History is one of the ways of being of time, but not the only one; therefore, there are other kinds of temporalities that fit the artwork. From the historical and temporal assumptions, the paper problematizes ideas like the universality of beauty and the eternity of the Idea.
\end{abstract}

Keywords: Hegelian Aesthetics, aesthetic ontology, historicity, temporality, artwork.

Una de las características principales de la filosofía hegeliana es la introducción del tiempo y la historia en el sistema. En lo que sigue me interesa abordar la significación y consecuencias de esa introducción en el ámbito estético.

Como punto preliminar es necesario hacer al menos dos observaciones. La primera tiene que ver con la diversidad de textos y momentos en los que el pensamiento hegeliano se demora en el arte; diversidad que provoca la falta de unidad, esto quiere decir que no hay una y sólo una estética en Hegel (probablemente no la hay en ningún pensador, lo que hay son momentos del pensamiento que ciertas interpretaciones se esfuerzan por unificar). La segunda observación tiene que ver con la doble perspectiva desde la que se pueden abordar las ontologías estéticas -y considero que la de Hegel pertenece cabalmente a la historia de las ontologías estéticas; por un lado, se puede reflexionar sobre el papel que cumplen el tiempo y la historia en el arte y preguntar, por ejemplo, qué significa la construcción de una historia del arte y si el arte es esencialmente histórico. Por otro lado, se puede reflexionar sobre las consecuencias de la introducción de tiempo e historia para la estética en su relación con la ontología y por ende para la ontología misma, después se puede preguntar qué significa pensar el ser desde el tiempo y la historia (y tal vez incluso como arte).

Vale la pena señalar la doble perspectiva porque el pensar no se orienta siempre igual sino que depende de qué es lo que intente pensar en cada caso, y no es lo mismo pensar la historia y el tiempo para el arte, que pensar la historia y el tiempo para el ser a través del arte. 1

\footnotetext{
1 En esto he insistido en diversas ocasiones. La filosofía del arte se distingue sustancialmente de la ontología estética. Paradigmas de esa diferencia son la estética analítica del lado de la filosofía del arte
} 
De entrada se puede preguntar qué es lo que piensa la estética hegeliana, el arte y sus manifestaciones históricas o el espíritu manifestado en y como arte. Seguidamente se puede preguntar si hay transformaciones en los diversos momentos de la estética hegeliana, si a veces piensa más el arte y le hace más justicia o si a veces piensa más el espíritu y se pasa un poco de largo el arte.

Finalmente se puede considerar esto en el trayecto que va de El más antiguo programa de sistema del idealismo alemán a las lecciones sobre estética dictadas en la década de 1820 en Berlín, y enjuiciar si hay unidad y coherencia en el trayecto, o bien cuáles son las modificaciones que va sufriendo el pensar hegeliano en su transitar. $^{2}$

Una vez enunciado lo anterior sólo queda enmarcar brevemente el problema del tiempo $^{3}$ y la historia. Si distingo entre tiempo e historia es porque considero que el tiempo no se agota en la historicidad ya que hay diversos modos de darse el tiempo y distintos horizontes desde los que puede ser abordado, que van en los extremos del arco del tiempo físico al tiempo humano, por un lado y, por otro, del tiempo histórico-narrativo al tiempo intempestivo. ¿Cuál es el tiempo del arte, cuál es el que le incumbe idóneamente y cuál es el que funda? Estas interrogaciones no necesariamente se resuelven del lado histórico pues el arte no se agota en la historicidad. Ahora bien, cabe preguntar cuál tiempo ${ }^{4}$ es el que entra en juego en las reflexiones de Hegel sobre el arte. 5 Evidentemente el histórico cumple un papel fundamental,

y la hermenéutica del lado de las ontologías estéticas. Para una discusión más amplia sobre esto, $C f$. González Valerio, M. A., «La hermenéutica frente al arte contemporáneo o la publicidad como fenómeno hermenéutico», en Vattimo, G., Oñate, T., Núñez, A. y Arenas, F. (ed.), Politeísmo y encuentro con el Islam. Hermenéutica entre Civilizaciones II, Madrid, Dykinson, 2008; María Antonia González Valerio, «Apuntes para pensar la publicidad como fenómeno estético», en Estudios filosóficos: Revista de Filosofia del Instituto Superior de Filosofia, vol. LVI, no. 161 (2007), Valladolid, España.

2 Dejo al margen la amplísima polémica sobre las lecciones de estética de Hegel, sobre su fidelidad y autenticidad, sobre la "manipulación" de la versión de Gustav Hotho convertida en la edición oficial en las obras completas, sobre la recuperación contemporánea de otros cuadernos de apuntes, su edición y publicación. La introducción a la recientemente publicada G.W.F. Hegel, Filosofía del arte o estética (verano de 1826) con los apuntes de Kehler da cuenta de eso. Annemarie Gehtmann-Siefert dirige esta investigación. Cf. Gehtmann-Siefert, A. M., Einführung in Hegels Ästhetik, München, Wilhelm Fink, 2005. Para este artículo me centraré sobre todo en la edición Filosofía del arte o estética (verano de 1826) publicada por Abada/UAM (Madrid, 2006), más que en las Lecciones sobre estética que publica Akal (Madrid, 1989). La primera se basa en el cuaderno de Kehler, la segunda en el de Hotho.

3 Dice Hegel en el parágrafo 258 de la Enciclopedia de las ciencias filosóficas (México, Juan Pablos, 1974): "El concepto ni es en el tiempo ni temporal", eso lleva a pensar qué relación hay entre el concepto y el arte, entre el tiempo y la historia, y en por qué la Idea necesita temporalizarse. Estas preguntas irán, en parte, guiando las reflexiones que componen este artículo.

4 Sobre clasificaciones de los tiempos me permito mencionar la que hace Ricoeur, P., Tiempo y narración, 3 vols., México, Siglo XXI, 1998; quien sigue en parte la segunda intempestiva de Nietzsche.

${ }^{5}$ La estética de Hegel es indudablemente histórica, hay incluso una coincidencia entre la historia del arte y la historia del mundo; coincido en este punto con Stanguennec quien afirma que la historicidad 
pero no es seguro que sea el único. De cualquier modo, esta cuestión no alcanzaré a dilucidarla aquí ni es tampoco mi propósito, sólo lo enuncio porque es el marco en el que se insertan las presentes observaciones sobre el arte y el tiempo.

No es completamente cierto que la relación entre arte y tiempo haya dominado por entero la reflexión estética del último siglo, aunque tampoco es completamente falso. Algunas de las más pujantes problemáticas han tenido que ver con ese tema, e incluso algunas de las más contundentes posiciones teóricas. Baste mencionar $-\mathrm{y}$ de nuevo sólo para enmarcar el problema- la historización del arte en las recepciones marxistas y posmarxistas en las que el caso de Lukács es probablemente el más contundente; la temporalidad histórica y suprahistórica como constitución esencial del arte en las hermenéuticas gadameriana y ricoeuriana; y la temporalidad no histórica o incluso antihistórica con que Nietzsche piensa el arte y después Deleuze. No puedo dejar de mencionar en esto que la encrucijada del ser y el tiempo Heidegger la resuelve en más de un sentido del lado del arte.

Estas son algunas de las consecuencias teóricas del haberse instaurado radicalmente la relación entre arte y tiempo en los siglos XVIII y XIX. Uno de los momentos fundacionales de ello es por supuesto la estética hegeliana. En lo que sigue me concentraré en marcar cómo y en qué sentido se da esta relación en la estética de Hegel. La brevedad del texto me impone a exponerlo sólo como un esbozo.

El tema del arte se desarrolla en tres niveles; el tiempo y la historia serán decisivos de manera diferente en cada uno de ellos. ${ }^{6}$ El primer nivel corresponde al arte como manifestación sensible de la idea; el segundo a la historia del arte dividida en sus tres grandes momentos; y el tercero al sistema de las artes particulares. Me enfocaré sólo en el primer nivel, aunque no quiero dejar de considerar brevemente algo acerca del segundo y el tercero; para hacerlo me limitaré a mencionar dos de los grandes autores que cruzan por doquier las reflexiones estéticas de Hegel, a saber: Winckelmann y Lessing. Con el primero pensará la división de la historia del arte y el contexto de producción de una obra como determinante; con el segundo la clasificación de las artes y su jerarquización según lo espacial, lo temporal y el lugar que en ello ocupe la acción.

Siguiendo a Winckelmann, quien ya había divido el arte en periodos y había enfatizado las circunstancias en las que la obra es creada, Hegel introduce como

de la estética hegeliana significa que: "cada gran momento de la historia, periodizada dentro de la filosofía de la historia del mundo [...] representa un modo artístico de la conciencia de sí del absoluto", Stanguennec, A., Hegel, París, Vrin, 1997, p. 209.

6 En ese sentido, Gehtmann-Siefert señala que: "Se trata de una relación de la Idea -como Hegel formula junto con Kant: la 'idea de razón'- con la historia. Esta asociación acontece de manera comprensible 'estéticamente' en lo bello, sin embargo sólo se hace concreta en las artes, y ejemplar en la poesía", Gehtmann-Siefert 2005, op. cit. (nota 2), p. 57. Esto deja ver un claro paso que va de la relación entre la Idea y el ideal, a la historia del arte dividida en lo simbólico, clásico y romántico a finalmente el análisis de las artes particulares. 
referencia indispensable el contexto concreto de producción de la obra de arte y asegura que la belleza artística debe ser comprendida en términos históricos. ${ }^{7}$ La belleza artística, es, así, expresión de los más profundos valores de una civilización, como Hegel ha subrayado con insistencia.

Para Winckelmann ya no era necesaria la mimesis de la naturaleza, porque en el arte griego hay una selección de lo más bello que puede haber en la naturaleza. De lo que se trata, pues, es de la mimesis del arte. Esta es la instauración del punto de vista del arte; la belleza está en lo humanamente producido: "Las más puras fuentes del arte han quedado así abiertas: feliz el que las encuentre e imite. Buscar estas fuentes quiere decir salir al encuentro de Atenas [...]. Los conocedores e imitadores de las obras griegas encuentran en las obras maestras de estos no sólo la más bella naturaleza sino también algo más que la naturaleza". ${ }^{8}$

Winckelmann repara en la determinación espacio-temporal del arte y en que, por tanto, tiene historia. Esta visión histórico-cultural del arte se enfrenta a la mirada de lo clásico universal y eterno. Hay que tomar en cuenta las teorías de historia del arte para considerar el fenómeno en su historicidad.

Además de lo anterior, otra de las influencias de Winckelmann en Hegel muy notable consiste en que para este último la figura humana es la representación sensible más excelsa del arte clásico-griego, por ende, del espíritu; para el primero: "El objeto primero del arte es el hombre. Así pues, en el arte se puede decir y con más razón que Protágoras, que el hombre constituye la regla y la medida de todas las cosas"9.

Siguiendo la clasificación de Lessing, las artes temporales estarán por encima de las espaciales 10 , por ello va en sentido ascendente-progresivo de la arquitectura (mayor espacialidad) a la poesía (mayor temporalidad). El centro, por supuesto, está en la acción, hay un predominio de la acción (piénsese en la Poética de Aristóteles donde la tragedia se define como mimesis praxeos, es decir como representación de acciones) en los análisis de Hegel tanto de las obras concretas y singulares como del sistema de las artes particulares. ${ }^{11} \mathrm{La}$ acción está en el centro, porque ahí se da lo histórico; por eso pasa de la escultura a la poesía.

7 Cf. Wicks, R., «Hegel's Aesthetics», en Beiser, F. (ed.), The Cambridge Companion to Hegel, Cambridge University Press, 1993.

8 Winckelmann, J., De la belleza en el arte clásico, México, UNAM, 1959, p. 66-67.

9 Winckelmann, J., Historia del arte en la antigüedad, Barcelona, Folio, 2002, p. 49.

10 "Ahora bien, si la pintura, en virtud de los signos que le son propios, o de los medios de los que puede servirse para la imitación -signos y medios que sólo puede combinar en el espacio-, tiene que renunciar totalmente al tiempo, entonces las acciones progresivas, en tanto que progresivas, caen fuera de los temas que son propios de este arte, el cual debe contentarse con acciones simultáneas, o, todo lo más, con cuerpos que, por su posición, sugieran una acción continua. La poesía en cambio...", Lessing, G. E., Laocoonte, Madrid, Tecnos, 1990, p. 105.

11 En Hegel 2006, op. cit. (nota 2) dedica todo un capítulo de la parte general a analizar la acción, de la que dice: "Llegamos ahora a la unidad plena, a lo concreto de lo bello artístico, que se refiere al con- 
Para entrar ya directamente al tema del arte, el ideal y la Idea comenzaré por afirmar que el absoluto se representa estéticamente. Hay una relación esencial entre el arte y la idea, pues ésta es la primera manifestación del espíritu absoluto. ¿Qué tipo de relación es la que se da y por qué de entrada hay que pensarla como esencial? La relación entre el arte y la idea es histórica pero además es esencial porque ambos son constituidos a partir de dicha relación. Esto quiere decir que el arte será histórico y la idea también, no es sólo que la relación entre ambos lo sea, sino que si tal relación es esencial y constituyente de arte e idea, entonces éstos serán según el modo de la relación, por lo tanto y en este caso, históricos. ¿De dónde gana el arte su historicidad? ¿Por qué el arte es histórico? Aquélla no le viene de fuera, no es impuesta ni gratuita; no es que haya arte y después se historice, como si la narración de los diversos momentos por los que pasa fuera heterodiegética, i.e., narrada desde fuera de los acontecimientos. Por tanto, no se trata de pensar que hay arte egipcio y griego y romántico, y que entre ellos se puede trazar una línea histórica, porque entonces esa línea viene después y permanece fuera del arte egipcio y griego y romántico.

Si la relación ha de ser esencial, entonces la línea histórica tiene que pertenecer al arte mismo, y eso hace que sea necesaria y que no pueda ser de otro modo (en este esquema la línea de relación entre acontecimientos no podrá ser nunca rizomática en sentido deleuziano), eso hace que el arte egipcio devenga griego y éste devenga romántico. No se trata, entonces, de relatar la historia del arte sino de dar cuenta de la historicidad del arte.

$\mathrm{El}$ arte es esencialmente histórico, esto quiere decir que es en la historia donde el arte llega a ser lo que es y deja de ser lo que es, ambas cosas suceden en la historia y como historia. El arte, así visto, no es ninguna esencia eterna, idéntica a sí misma e inalterable en el paso del tiempo. El arte, al igual que el organismo vivo, tiene un nacimiento y una decadencia, tal vez incluso una muerte. El arte no ha sido siempre y no tendría por qué ser siempre, ya que una de las cosas que se introduce con la temporalidad es la finitud, un momento en la negatividad hegeliana, un zaratustreano hundirse en su ocaso.

tenido y que en conjunto puede entenderse como acción", p. 135. El tema vuelve a aparecer en el análisis de la forma artística romántica, y después en la parte especial. Es de notar que incluso las artes espaciales, como la escultura, son por momentos enfocadas desde la acción -o la falta de ella-: "La escultura ha de exponer al dios para sí mismo en su objetividad sin la movilidad de la acción determinada, sino como abismado en sí, en su simple calma y sublimidad. Esta calma autónoma, la clausura del dios en sí, es la determinación esencial de las obras escultóricas. Actos, acciones y sentimientos están proscritos de ella [...]. En la escultura no se da tal subjetividad, sino la objetividad en su forma absoluta; deja libre curso a lo espacial", ibidem, p. 407. Sobra decir que en esto está siguiendo a Winckelmann y su descripción del Laocoonte a la que Lessing replicará después con énfasis. Ni qué decir del análisis que hace Hegel de la poesía dramática y el papel que juega ahí el pathos ético (como lo activo de una acción). 
El arte y la belleza, las bellas artes, adquieren con esto temporalidad y finitud. De modo tal que el arte no es, sino que es siendo, va siendo. 12

¿Qué significa para el arte y para la belleza ganar el punto de vista histórico, qué significa en esto historizar? ¿Por qué separar arte y belleza o por qué reunirlas bajo el título de bellas artes? Historizar la belleza, quitarle eternidad e inmanentizarla es un proceso harto distinto al que sufre el arte, primero al embellecerse y ganar atributos metafísicos y separarse radicalmente del resto de los entes en el siglo XVIII y después al inmanentizarse hasta casi desaparecer en la banalidad durante el siglo XX y lo que va del XXI. Pero este proceso por el que pasa el arte en su relación con lo bello no es el tema que aquí me ocupa, me basta sólo con mencionarlo para evocar ciertos problemas, por ejemplo, pensar qué quiere decir el punto de vista histórico para el arte y cuál es el sentido y el lugar de una historia del arte. Dejaré esos temas sólo evocados para centrarme en lo que aquí me concierne.

La historicidad como elemento constituyente del arte, decía líneas arriba, depende, en términos hegelianos, de la relación que establezca con la Idea. La relación es histórica y se historiza. Ahora bien, hay que preguntar cómo se da esta relación. Primero que nada es necesario puntualizar que no se trata de un platonismo estético y esto le da al arte ya desde el inicio un estatuto completamente distinto al de ser imitación de algo que le preexista y preceda. ${ }^{13}$

Annemarie Gehtmann-Siefert asegura que la recepción de la estética de Hegel y la falta de actualidad de la que se le ha acusado en los últimos tiempos depende mucho del platonismo que se le atribuye. Por eso, para ella pensar la manifestación sensible de la Idea conlleva afirmar que la Idea preexiste, que la Idea (de lo bello, como la de Platón, e.g., en Fedro) sólo es manifestada sensiblemente en el arte. Este ser "sólo manifestada" implica un menosprecio de lo sensible. Frente a esa posición el Ideal ha de ser considerado como "Dasein", "Existenz" y "Lebendigkeit"; haciendo énfasis con estas categorías en el carácter vivo y móvil del Ideal, en su irse dando históricamente en contraposición a una Idea (platónica) fija e inmóvil en el topos uranos. 14

\footnotetext{
12 Este es precisamente el modo en el que Hans-Georg Gadamer, a mi juicio siguiendo a Hegel, considera el arte en sus últimos escritos, $C f$. «Palabra e imagen (tan verdadero, tan siendo)», en Estética y hermenéutica, Madrid, Tecnos, 2001.

13 En ese sentido, señala Hegel en un primer momento: "imitar la naturaleza es un deleite muy limitado; el hombre debe encontrar mayor deleite si produce algo suyo, inventado por él: instrumentos técnicos, una obra escrita, o especialmente algo científico, que le corresponda completamente en propiedad. Ha de estar orgulloso de tal invención, que le es original, que él no ha imitado", Hegel 2006, op. cit. (nota 2), p. 65. En el mismo tenor se pronuncia en el parágrafo 558 de la Enciclopedia de las ciencias filosóficas: "De este modo se liquida el principio de la imitación de la naturaleza en el arte." 14 "Hegel parte de esto, de que el Ideal sea existencia (Dasein, Existenz) y vida (Lebendigkeit) de la Idea, es decir, que el Ideal re-presenta (darstelle) y representa (vorstelle) a la Idea en su realidad (Realität) histórica", Gehtmann-Siefert 2005, op. cit. (nota 2), p. 30.
} 
Tal vez uno de los mejores ejemplos de una posición así es el libro X de la República de Platón donde la cama que pinta el pintor es literalmente una copia de la cama del carpintero, la que a su vez es una copia de la idea de cama. ${ }^{15} \mathrm{La}$ pintura así considerada trata con algo distinto de sí, algo que le precede y le es completamente ajeno, pues la pintura de la cama en nada altera la idea de cama. Esto ilustra el platonismo estético ${ }^{16}$, aunque no hay que perder de vista que la posición de Platón sobre la mimesis es mucho más compleja.

¿Qué pasa con el arte en Hegel? ¿Está postulado como una representación de algo que le precede? ¿Se relaciona con algo distinto de sí? ¿Puede ser pensado en términos miméticos?

Si Hegel puede ser incluido en las ontologías estéticas es, a mi juicio, porque la relación que hay entre el arte y, digamos, lo real no es inesencial, es decir, que lo real se constituye también desde el arte y por lo tanto no puede ser una instancia que le preceda y a la que meramente se limite a copiar. Si el arte es la manifestación sensible de la Idea (der sinnliche Scheinen der Idee), la Idea no es previa a su manifestación sensible, o mejor dicho, el modo en que la Idea es al manifestarse sensiblemente sólo lo es en la manifestación. ${ }^{17}$

15 "Conforme a lo dicho resultan tres clases de camas: una, la que existe en la naturaleza, que, según creo, podríamos decir que es fabricada por Dios, porque, ¿quién otro podría hacerla? [...] Otra la que hace el carpintero [...] Y otra, la que hace el pintor; ¿no es así? Por tanto, el pintor, el fabricante de camas y Dios son los tres maestros de esas tres clases de camas”, Platón, República, 597b.

16 Derrida ejemplifica muy bien en qué consiste el platonismo estético comprendido también como ontoteología, me permito, por ello, citarlo ampliamente: "Es justamente lo ontológico: la posibilidad presunta de un discurso sobre lo que es, de un logos que decide y es decidible de o sobre el on (serpresente). Lo que es, el ser-presente (forma matricial de la sustancia, de la realidad, de las oposiciones entre la forma y la materia, la esencia y la existencia, la objetividad y la subjetividad, etc.) se distingue de la apariencia, de la imagen, del fenómeno, etc., es decir, de lo que, presentándole como serpresente, le dobla, le re-presenta y a partir de ello lo reemplaza y le des-presenta. Hay, pues, el 1 y el 2, lo simple y lo doble. Lo doble viene después de lo simple, lo multiplica después [...] la imagen sobreviene a la realidad, la representación al presente en presentación, la imitación a la cosa, lo imitante a lo imitado. Hay en primer lugar lo que es, la «realidad», la cosa misma [...] luego, lo imitante, [...] La discernibilidad, al menos numérica, entre lo imitante y lo imitado, ése es el orden. [...] lo imitado es más real, más esencial, más verdadero, etc., que lo imitante. Le resulta anterior y superior”. Derrida, J., «La doble sesión» en La diseminación, Madrid, Fundamentos, 1975, p. 288.

17 "Pero a la esencia misma le es esencial la apariencia; la verdad no sería tal si no pareciera y apareciera, si no fuera para alguien, para sí misma tanto como para el espíritu en general. [...] la apariencia del arte tiene la ventaja de que ella misma va más allá de sí y apunta desde sí a algo espiritual que debe acceder a la representación a través suyo, frente a lo cual la apariencia inmediata no se presenta a sí misma como ilusoria, sino más bien como lo efectivamente real y lo verdadero, mientras que, en cambio, lo inmediatamente sensible vicia y oculta lo verdadero." Hegel 1989, op. cit. (nota 2), p. 12. En el parágrafo 556 de la Enciclopedia de las ciencias filosóficas asevera que: "La forma de este saber es, en cuanto inmediata (el momento de la finidad del arte), por una parte un romperse en una obra de existencia externa y común, en el sujeto que produce la obra y en el que la contempla y la adora; por otra parte, es la intuición concreta y la representación del espíritu absoluto en sí como ideal". El subrayado es mío. Vale la pena reparar en que además de pensar el arte como representación del espí- 
Este punto es de fundamental importancia ya que de él depende el estatuto ontológico que tiene el arte al interior del sistema hegeliano. El arte no es y no puede ser ilustración de algo que le preceda, porque si así fuera sería superfluo e innecesario. El desarrollo histórico de un pueblo está íntimamente vinculado con sus manifestaciones artísticas, esto quiere decir que aquello que ese pueblo sea lo es también gracias al arte; sus verdades morales, políticas, culturales, etc., ${ }^{18}$ llegar a ser también en y como arte. No es que primero se tenga la certeza clara y distinta de tal verdad moral y después simplemente se le ilustre en el arte; no se trata de un libro de doble columna en el que el arte sería la columna plástica accesoria al concepto.

La posibilidad del arte se cifra en otro lugar al de la ilustración de lo previamente sabido. Hegel tiene razón en su análisis de la fábula esópica según el cual en este tipo de relatos la verdad es sabida previamente y la fábula es sólo el medio ilustrativo para enunciarla; ya sabíamos que hay que trabajar igual en tiempos de bonanza que de carestía, ¿necesitábamos a la hormiga y la cigarra para comprenderlo? La fábula del tipo esópico "no es poesía libre, verdadera obra de arte, sino que se trata de lo vulgar, lo ingenioso, para extraer en una relación subordinada alguna doctrina a partir de una relación natural, para aprehenderla como exposición de alguna enseñanza."19 La función del arte no es ilustrar o incluso adornar una verdad previamente sabida. Son los cuentos infantiles los que ilustran -y sólo ilustran- verdades morales del dominio común; verdades morales que en todo caso han sido ya presentadas y justificadas por discursos previos. El arte no ilustra sino que manifiesta, hace ser lo que antes no era y desde ese momento es; momento de revelación, lo que acontece lo hace ahí y en la experiencia. Si todavía hay arte su función, su poder de detección ontológica no está del lado del particular, del singular concreto sino del universal.

El desarrollo del espíritu se da en el arte y no puede llegar a ser lo que es más que a través de las manifestaciones sensibles; por ende, el arte aparece aquí como una necesidad ontológica y vital, no sólo es adorno, sino que tampoco es autónomo en un sentido estético fuerte. La autonomía estética del arte, su gratuidad vendrá mucho después, si es que acaso ha llegado, si es que ha acaecido una "muerte" del arte en su función de manifestación del espíritu.

Hay que tener cuidado, entonces, con la "manifestación" (Scheinen) o "representación" (Darstellung) en el arte porque puede hacer interpretar apresuradamente que el arte se limita a una función imitadora, más que creadora. Este punto se puede argumentar cuando menos en dos vertientes: por un lado, analizar en térmi-

ritu, se deja ver también una noción de arte como existencia exterior que conduce hacia el creador y el receptor, temas que merecen un abordaje separado.

18 "En las obras de arte han depositado los pueblos sus intuiciones y representaciones internas más ricas en contenido, y a menudo constituye el arte bello la clave, la única en muchos pueblos, para la comprensión de la sabiduría y la religión", Ibidem.

19 Hegel 1989, op. cit. (nota 2). 
nos metafísicos estrictos el sistema hegeliano y el modo de ser de la Idea, por otro, atendiendo a la relación entre Idea e Ideal en la estética. Es la segunda vertiente la que seguiré aquí.

Annemarie Gehtmann-Siefert ha hecho de este punto uno de los centrales en su análisis de la estética hegeliana, y ha sostenido que la versión de Hotho presenta un platonismo estético del cual el mismo Hegel estaría muy lejos. Ciertamente a veces esa versión hace aparecer un tinte platonista en la argumentación:

[...] sólo en esta su libertad es el arte arte verdadero, y sólo cumple su suprema tarea cuando se sitúa en la esfera común a la religión y a la filosofía y es solamente un modo de hacer conscientes y de expresar lo divino, los intereses más profundos del hombre, las verdades más comprehensivas del espíritu. En las obras de arte han depositado los pueblos sus intuiciones y representaciones internas más ricas en contenido [...] El arte comparte esta determinación con la religión y la filosofía, pero de la manera peculiar en que representa lo supremo también sensiblemente, y con ello lo aproxima al modo de manifestación de la naturaleza, a los sentidos y al sentimiento. ${ }^{20}$

"Hacer consciente (zum Bewusstsein zu bringen)", "expresar (aussprechen)", "depositar (niederlegen)", "representar (darstellen)" son términos que parecen aludir a un cierto carácter secundario del arte, el cual además queda en desventaja ontológica y epistémicamente frente a la religión y la filosofía.

Como primera consideración se puede mencionar que si el arte fuera sólo el depositario de las intuiciones de los pueblos, ¿cuál sería el sentido de su historicidad? Los pueblos van desarrollándose, transformándose históricamente y como el arte es exterior a estas transformaciones la historicidad no le es propia, sino ajena y accidental, porque el arte mismo es accidental para el pueblo.

Vista desde la historia, esta perspectiva es poco afortunada o tal vez incluso tramposa porque las preguntas que suscita son improcedentes. ¿Se hubiera podido llegar a la tesis de la libertad, igualdad y fraternidad sin la pintura renacentista, sin la exaltación plástica de lo humano? La pregunta es a todas luces improcedente ya que está hecha retrospectivamente y hablar de la absoluta necesidad de la pintura renacentista para alcanzar los ideales ilustrados franceses es contar la historia con un giro de tuerca que hace verla necesaria, como si no hubiera podido ser de otro modo, pero ello se logra sólo gracias a la retrospectividad con que se relatan los acontecimientos.

El arte no se limita a reproducir una época, a ser sólo el espejo en el que se reflejan las características más propias y más íntimas, sino que tiene que coadyuvar a producirlas; en términos hegelianos: la libertad no es asequible sin haber pasado por la manifestación sensible.

20 Hegel 1989, op. cit. (nota 2), p. 11. (Vorlesungen über die Ästhetik I, Frankfurt am Main, Suhrkamp,1999, p. 20-21). 
Al pensar la libertad, el tema de la estética será más la función social y moral del arte -siguiendo el proyecto de Kant en la Crítica del juicio ${ }^{21}$ en cuanto a lo sublime y a las ideas estéticas - que la hipostatización de lo bello clásico -y divino por tanto.

Lo bello es símbolo de la moral, donde precisamente el mundo moral y cultural del ser humano es lo que será subrayado -y conformado por el arte mismo-, en vez del sentimiento de placer en la contemplación de lo bello al estilo del juicio de gusto kantiano. El objeto bello será libertad, una "rara" especie de heautonomía, de ahí que Schiller lo pueda considerar como libertad en apariencia, es decir, el aparecer de la libertad.

$\mathrm{El}$ arte tiene un efecto moral, histórico y cultural 22 , por ende, lo bello no puede quedar reducido a la interioridad subjetiva, ni del juicio de gusto, ni del sentimiento estético; en última instancia, ni de la educación individual. Lo bello no tiene que ver con la interioridad del sujeto, sino con la historia, con la idea de la razón y con la sociedad. De ahí la crítica de Gadamer al kantismo 23 como "estatización” del arte, como reducción al juicio de gusto, al sentimiento de lo bello. El arte debe llegar más lejos que a las "capacidades subjetivas".

El acento está en el efecto histórico del arte mucho más que en las figuras (bellas), en todo caso, la belleza en Hegel tiene que ver más con los efectos sociohistóricos del arte en relación con la moral y la libertad que con la contemplación "quieta" de la forma bella. Esto me despierta la siguiente pregunta: ¿Se hace sensible-intuible en lo bello la relación del arte con la historia?

El placer frente a lo bello queda desplazado frente al efecto histórico del arte. Las consecuencias de esto se dejarán sentir en las estéticas marxistas y posmarxistas, en la recuperación de la verdad del arte que emprendieron, por ejemplo, Heidegger y Gadamer en el siglo XX, y, por supuesto, en las mismas corrientes artísticas (pienso solamente como muestra la pintura neorrealista o social-histórica en la que se pueden inscribir de Diego Rivera y David Alfaro Siqueiros al estadounidense Edward Hopper).

Comprender la relación entre lo bello, el arte y la historia requiere demorarse en la relación entre Idea e Ideal. Dice Hegel: "Ahora bien, si lo vivo fuera tal como lo hemos determinado, entonces sería bello. Pues en lo determinado está presente el concepto, que es para sí mismo necesariamente, y la realidad viene determinada únicamente mediante el concepto". ${ }^{24} \mathrm{Sin}$ embargo, lo vivo no es bello, requiere de

21 Cf. Kant, I., Crítica del juicio, particularmente el parágrafo 59.

22 Siguiendo de nuevo "El más antiguo programa de sistema del idealismo alemán", A. GehtmannSiefert considera que es necesario que las ideas de la razón devengan mitológicas y estéticas para que puedan efectuarse y realizarse en el mundo de la praxis, es decir, que tienen que devenir sensibles, $C f$., Gehtmann-Siefert 2005, op. cit. (nota 2), p. 56.

23 Cf. Gadamer, H. G., Verdad y método, Salamanca, Sígueme, 1996.

24 Hegel 2006, op. cit. (nota 2), p. 121. 
la transformación del arte para que aparezca tal y como lo hemos determinado. Ahora, sobre la Idea señala que: "Idea no significa otra cosa que la unidad del concepto y la realitas, en general, el concepto realizado". 25 Con esta definición de Idea, Hegel no pretende disolver la tensión entre el concepto y la realidad, como si lo natural no representara ninguna oposición, como si el mundo fuera sin más e inmediatamente el reflejo de lo humano. El mundo tiene que llegar a ser nuestra morada y ha de llegar a serlo poéticamente (Heidegger), esto quiere decir que el arte realiza un trabajo sobre la realidad para transformarla, para hacerla humana, para hacerla Ideal:

Si la idea en su realización fuese tan lejos como acabamos de decir, entonces tendríamos la determinación de lo bello como tal o el ideal. Idea e ideal son tan diferentes que la idea es, en efecto, realización del concepto, aunque nosotros permanezcamos en ella para captar pensando este modo de la realidad, mientras que el ideal también se representa existiendo en el modo de la realidad, pero de modo que ésta permanece bajo el dominio del concepto. [...] El hombre, el hombre existente, es idea, y sería ideal si existiese únicamente conforme a la idea; pero no es esto sólo, sino que también es hombre naturalmente existente. El concepto, al entrar en la existencia, accede con ello a la necesidad exterior, a la conexión y realización efectiva con otras existencias, y lo natural comienza a no ser ya adecuado a los ideales. ${ }^{26}$

Precisamente porque lo natural comienza a no ser ya adecuado a los ideales, la realidad tiene que elevarse, tiene que ser formada y configurada y ese es precisamente el trabajo del arte en tanto manifestación exterior, a diferencia de la interioridad en la que se mueve la religión.

Hay que tener presente que en este sistema no basta el pensamiento como pura abstracción, no basta el universal abstracto; sino que el pensar tiene que ponerse a prueba en lo real y emerger de lo real, no lo puede dejar de lado; no es suficiente la resolución de los conflictos en un reino utópico imaginario, no es suficiente ni el noúmeno kantiano para la libertad, ni tampoco la educación estética de Schiller.

La libertad, la disolución de dicotomías, la unidad y la armonía tienen que ser alcanzadas en el reino de este mundo, en la vida pública y comunitaria, y no sólo en la interioridad del pensamiento de quien piensa.

La Idea, entonces, tiene que manifestarse, tiene que hacerse real y concreta para alcanzarse a sí misma, para llegar a ser lo que es; el arte es una de esas exterioriza-

\footnotetext{
25 Ibidem, p. 115. En la edición de Hotho esta tesis aparece así expresada: "Hemos llamado bello a la idea de lo bello. Esto ha de entenderse de tal manera que lo bello mismo debe ser captado como idea, y ciertamente como idea con forma determinada, como ideal. Ahora bien, la idea en general no es nada más que el concepto, la realidad del concepto y la unidad de ambos. [...] Tal unidad entre el concepto y la realidad es la definición abstracta de idea". Hegel 1989, op. cit. (nota 2), p.81.

26 Ibidem, p. 123-125. El subrayado es mío.
} 
ciones, pero no es cualquier exteriorización, sino una donde lo contingente se abole para presentar sólo lo necesario, por eso el arte es superior a la planta y al animal:

De un retratista que deba llevar al lienzo una determinada fisonomía, se dice, en general, con reprobación, que él adorna. Pues si es un verdadero pintor, un artista, entonces tiene que adular. Debe omitir del rostro en cuestión todo signo de exterioridad como pelillos y otras sutiles determinaciones o tipos de piel, que corresponden al reino de la contingencia y de la vida precaria. [...] El arte elimina toda indigencia de la vida exterior, de la existencia, y vuelve a llevar hasta su ideal a lo real, liberado de las contingencias de la naturaleza. ${ }^{27}$

La realidad formada y conformada a partir del espíritu es la objetividad del arte, absolutamente necesaria para el autoconocimiento del espíritu: "es necesario que lo interno pase a ser fenómeno; pues a la idea le pertenece la realidad, y un espíritu que no aparezca no es algo verdadero. La esencia debe aparecer" 28.

Pero lo real inmediato no refleja al espíritu, éste no se encuentra a sí mismo en cualquier fenómeno ${ }^{29}$, el mundo natural en tanto mera naturaleza es imperfecto y contingente, lo vivo es sólo eso, lo orgánico vivo. ¿Podríamos encontrarnos a nosotros mismos en cualquier fenómeno, cualquier cosa alcanza a ser el espejo del alma, en cualquier exterioridad nos elevaremos para llegar a ser lo que somos? Para Hegel la respuesta es clarísima; llegaremos a ser lo que somos también a partir de lo externo, pero no todo lo exterior es cumplimiento de estas demandas metafísicas; sólo lo mejor de la exterioridad, i.e., sólo lo bello. 30

Dice Hegel: "[...] si lo vivo fuera tal como lo hemos determinado, entonces sería bello". 31 Pero lo vivo no es tal y como lo hemos determinado más que en el arte (aunque esto da mucho que pensar porque lo vivo también lo hemos determinado en y con la tecnología, la tecnociencia, la publicidad, la configuración de los espacios-tiempos urbanos, etc.).

27 Ibidem, p. 125-127. El subrayado es mío. En esto se deja oír claramente la voz de Winckelmann, me permito citarlo para evidenciarlo: "la naturaleza puede ser superada por el arte. [...] Pero la naturaleza, aun cuando en la formación de sus individuos tienda a lo perfecto, encuéntrase casi siempre impedida por la materia y por los numerosos accidentes a que está sujeta la humanidad, de tal manera que no puede llegar al fin que se propone; tan es así que será casi imposible encontrar hombre alguno de belleza perfecta en todas sus partes." Winckelmann, J., Lo bello en el arte, Buenos Aires, Nueva visión, s/a, p. 90.

${ }^{28}$ Hegel 2006, op. cit. (nota 2), p. 121.

29 Quizá el espíritu sí se encuentre a sí mismo en la banalidad y contingencia que en más de un sentido constituyen el reino del arte contemporáneo, quizá hoy sí se encuentre en la rata muerta, en la lata de Campbell's, en la botella vacía; pero digo solamente quizá porque no es fácil resignarse a la banalidad.

30 ¿Y por qué hoy el arte parece querernos decir que estamos también en el cadáver del tiburón? Pienso con esto en la obra de Damien Hirst Imposibilidad fisica de la muerte en la mente de alguien vivo en la que en un tanque lleno de formaldehído se expone un tiburón.

31 Hegel 2006, op. cit. (nota 2), p. 121. 
De ese modo, el arte sólo puede darse en el tiempo y como tiempo; se trata de un proceso, de un proceso para llegar a ser lo que somos, 32 y lo que somos no está predestinado ni dado de antemano, sino que somos tiempo, temporalidad y finitud que se desenvuelve históricamente, y se desenvuelve también como arte, también aunque no exclusivamente pues no sólo nos hemos dado un ser artísticamente y configurado el espacio-tiempo desde el arte. No solamente y no exclusivamente dirá Hegel, pues al arte le siguen, como sabemos, religión y filosofía. ${ }^{33} \mathrm{Y}$ así, históricamente y como historia habremos pasado de la religión del arte a las ontologías estéticas -no digo a la "filosofía del arte" porque eso quiere decir otra cosa, quiere decir estética como disciplina filosófica. Y en este punto quisiera sólo evocar la vecindad de la filosofía con el poeta que canta a la que Heidegger ${ }^{34}$ alude elegíacamente, así como a la separación de filosofía y poesía que María Zambrano ve en nuestros días ${ }^{35}$; evocar esos momentos que hablan de la relación entre arte y filosofía pero después de haber hecho el camino, después de haber trascurrido la historia (¿la historia del arte?).

32 A. Gehtmann-Siefert insiste acertadamente en que hay que subrayar la función cultural que tiene el arte en Hegel, frente a cualquier idea de autonomía estética (las consecuencias de esa autonomía las hemos visto bien en el siglo XX con los neo y poskantismos): "No se trata de la 'autonomía' del arte, sino de su determinación cultural, de su significado para los seres humanos y para las configuraciones de la sociedad humana, en las que el individuo se desarrolla a sí mismo", Gehtmann-Siefert 2005, op. cit. (nota 2), p. 32. Una de las discusiones centrales de la autora ha sido tratar de rescatar a Hegel de dos puntos que han sido particularmente polémicos en su recepción: el clasicismo y la muerte del arte. Para ello, se sirve de una interpretación más histórica que metafísica de la estética hegeliana -con la que coincido ampliamente-, es decir, deja de lado la manifestación sensible de la Idea a favor de los efectos históricos y de la vida histórica de la Idea. Esta función cultural va de la mano con el efecto histórico del arte para un cronotopo determinado - lo que choca de frente con las tesis de la autonomía del arte y su universalidad formal de corte kantiano. La autora, entonces, realiza una apología de Hegel historizando la estética, esto es, inmanentizándola, y esa interpretación me parece por demás sugerente. Por eso mismo, ella insinúa que el arte hay que leerlo más como fenómeno que como sistema, que el sistema en última instancia no aparece por ningún lado en las lecciones de estética. Insiste, pues, en que "El Ideal es la realidad estética y mitológica de la Idea", ibidem, p. 50 (esto último siguiendo de cerca el El más antiguo programa de sistema del idealismo alemán).

33 Arte, religión y filosofía son elevación hacia lo verdadero se distinguen así: 1. Arte. Intuición, saber inmediato y sensible (anschauende Bewusstsein). 2. Religión. Conciencia representativa (vorstellende Bewusstsein). 3. Filosofía. Conciencia pensante (denkende Bewusstsein). No es seguro que estos tres grandes momentos del saber y del ser: arte, religión y filosofía puedan ser distinguidos; ya en la Fenomenología del espíritu se hablaba de la religión del arte, tal vez hoy más que nunca la relación, casi con-fusión del arte con la filosofía nos recuerde aquel momento griego sólo que del lado del pensamiento del pensamiento: "si es la cosa más excelsa, se piensa a sí mismo y su pensamiento es pensamiento de pensamiento." Aristóteles, Metafísica, 1074b30.

${ }^{34}$ Cf. Heidegger, M., Desde la experiencia del pensar, Madrid, Abada, 2005.

35 "Y es en esta época cuando pensamiento y poesía se desligan, se ignoran. Y es también, cuando por primera vez, la poesía responde a la actitud imperialista del pensamiento filosófico, aspirando ella igualmente, a idéntico poder y haciéndose absoluta. Y es que la poesía ha adquirido conciencia en esta era de la conciencia." Zambrano, M., Filosofía y poesía, México, F.C.E., 1996, p. 82. 
Y con la historia la belleza se desvanece; se desvanece como universal y eterna, ${ }^{36}$ como forma bella resplandeciente lejos de este mundo de devenir y muerte. Con la historia la belleza se encarna, se hace humana, se hace figura humana, se hace pasión humana, afecto humano... y después se hace muerte.

No hay contemplación eterna de la Idea, sino el acontecimiento histórico y finito de la Idea; el arte será pensado después como acontecimiento (en Heidegger, en Gadamer, en Deleuze, por citar sólo a algunos); incluso como acontecimiento creador de la Idea pero sin hipostasiarla, sin hacer que la Idea sea idéntica al desarrollo de la historia humana. Precisamente por eso el arte para las filosofías posteriores aparecerá como "el mago que salva" 37 de la secularización absoluta que disuelve todo en la historia humana. El arte, como dice Gadamer, es siempre más; ser más sin dejar de ser demasiado humano, sin ser tampoco divino (pues no se trata de tirar líneas de fuga hacia la trascendencia), pero sin ser tampoco sólo la historia, sólo el tiempo histórico. El arte también es el rayo en medio de la noche, es también lo intempestivo: "Quien no es capaz de instalarse, olvidando todo el pasado, en el umbral del momento, el que no pueda mantenerse recto en un punto, sin vértigo ni temor, como una Diosa de la Victoria, no sabrá qué cosa sea la felicidad y, peor aún, no estará en condiciones de hacer felices a los demás."38

\footnotetext{
36 Por ello, es posible interpretar que una de las principales notas del historicismo hegeliano es un fortísimo ímpetu de secularización, en ese sentido, nos damos cuenta, el espíritu se da cuenta de que "lo que aparece dado, eterno o natural es de hecho el producto de la actividad humana y de hecho de una actividad en un contexto cultural específico", Beiser, F. C., "Hegel's Historicism", en Beiser 1993, op. cit. (nota 7), p. 272. La historia, entonces, aniquila la trascendencia, el universal eterno e intemporal de, por ejemplo, la belleza.

${ }^{37}$ La frase es de Nietzsche en El nacimiento de la tragedia.

38 Nietzsche, F., Sobre la utilidad y los perjuicios de la historia para la vida, Madrid, Edaf, 2000, p. 38.
} 